\title{
Pemanfaatan Algoritma Machine Learning untuk Segmentasi Pelanggan Berbasis Data Konsumsi Listrik di PT PLN XYZ
}

\author{
Rizqa Afthoni ${ }^{1 *}$, Mirza Hamdhani ${ }^{2}$, Ardianto $^{3}$, Aprilia Fitri Karimah ${ }^{4}$, Harry Patria ${ }^{5}$ \\ Jurusan Analitika Bisnis, Fakultas Magister Manajemen Teknologi, \\ Institut Teknologi Sepuluh Nopember Surabaya, Indonesia \\ (*rzafthoni@gmail.com)
}

\begin{abstract}
Abstrak - Salah satu strategi yang diterapkan untuk menganalisis karakteristik pelanggan PT PLN XYZ dalam menggunakan listrik adalah Customer Relationship Management. Dalam penelitian ini, data pelanggan tersegmentasi adalah pelanggan paskabayar dengan berbagai tarif, daya, konsumsi kWh dan jumlah tagihan listrik di dalamnya. Masing-masing dari variabel tersebut kemudian dikombinasikan, sehingga terbentuklah segmentasi karakteristik pelanggan PT PLN XYZ berdasarkan variabel tersebut. Hasil dari segmentasi pelanggan, dapat dijadikan dasar untuk menentukan arah kebijakan dalam membuat strategi pelayanan pelanggan yang dipadukan dengan Customer Relationship Management. Dalam riset ini Customer Relationship Management dijadikan sebagai dasar strategi pelayanan pelanggan yang dipadukan dengan hasil segmentasi pelanggan, sehingga arah pengambilan keputusan lebih terarah. Setiap segmentasi mempunyai insight atau proposisi nilai sesuai dengan karakternya masing-masing. Proposisi nilai tersebut dilakukan dengan memahami data segmentasinya, untuk kemudian kita bandingkan dengan karakter konsumsi listriknya. Selanjutnya, dari proposisi nilai segmentasi tersebut dapat diambil arah strategi pelayanan pelanggan yang sesuai dengan kebutuhan dari segmen-segmen tersebut. Metode untuk segmentasi pelanggan menggunakan algoritma machine learning clustering K-means. Dari hasil segmentasi, terdapat 46 pelanggan merupakan clustering kelas pertama profitable customer dan 19.989 pelanggan merupakan clustering kelas kedua less-profitable customer. Selanjutnya, dilakukan strategi Customer Relationship Management pada tiap segmentasinya. Untuk profitable customer, strategi hubungan pelanggan dilakukan dengan Bisnis to Bisnis dan Customer Business Development, sedangkan untuk less-profitable customer dilakukan Continuous Replenishment program serta Retail Account Marketing. Hasil segmentasi pelanggan tersebut dapat digunakan sebagai data pendukung pengambilan keputusan bisnis di PT PLN XYZ.
\end{abstract}

Kata kunci: clustering; Customer Relationship Management; machine learning segmentasi

\section{PENDAHULUAN}

Dalam dunia bisnis, diperlukan segmentasi pelanggan untuk pemasaran. Pemasaran sangat penting untuk dijalankan, agar pelanggan mengetahui tentang product knowledge atau layanan yang dihasilkan dari bisnis. Saat melakukan pemasaran perusahaan perlu melakukan targeting, karena beragamnya pelanggan dari karakter, perilaku, maupun kebutuhan. Oleh karena itu, perlu dibuat segmentasi menurut karakter, perilaku, maupun kebutuhan yang sama. Dengan melakukan segmentasi pelanggan, perusahaan bisa mengalokasikan sumber daya yang sesuai dan tepat sasaran ke target segmentasi pasar.

Konsep pemasaran yang dipakai selama ini masih menggunakan konsep yang konvensional, segmentasi hanyaberdasarkan golongan tarif dan daya, sehingga konsep-konsep pelayanan pelanggan hanya didasarkan pada pelanggan per-tarif dan daya. Padahal ketika dianalisa kembali data konsumsi, tarif, daya, jumlah tagihan ada kecenderungan karakteristik yang sama. Segmentasi tersebut dapat menjadi dasar manajemen atau pengambil keputusan untuk membuat produk layanan perusahaan listrik yang sesuai dengan pasar segmentasinya. Dalam membuat segmentasi ini, kita menggunakan algoritma machine learning K-means, hasil dari segmentasi pelanggan tersebut akan menjadi dasar arah customer relationship management dalam pengembangan strategi peningkatan pelayanan pelanggan.

\section{STUDI LITERATUR}

CRM adalah strategi yang bercerita tentang bagaimana memaksimalkan profitabilitas melalui pengembangan kepuasan pelanggan. CRM merupakan konsep strategi yang menitikberatkan pada pelayanan pelanggan. CRM merupakan proses bagaimana mendapatkan, mempertahankan dan mengembangkan pelanggan agar lebih profitable. 
Menurut Newell yang dikutip oleh Kartika Imasari, “Customer Relationship Management (CRM) adalah sebuah modifikasi dan pembelajaran perilaku konsumen setiap waktu dari setiap interaksi, perlakuan terhadap pelanggan dan membangun kekuatan antara konsumen dan perusahaan". Menurut Kotler dan Keller, "CRM atau manajemen hubungan pelanggan adalah proses mengelola informasi secara rinci tentang masing-masing pelanggan. CRM mengelola semua "titik kontak" pelanggan untuk memaksimalkan loyalitas pelanggan". Titik kontak pelanggan adalah pelanggan dapat menghubungi dan mendapatkan informasi mengenai produk atau jasa. Sedangkan menurut Gordon (2002) "CRM is a series of strategies and processes that create new and mutual value for individual customers, build preference for their organizations and improves business result over a lifetime of association with their Customers". Ada empat kemampuan utama strategis dalam CRM (Gordon, 2002) yaitu: teknologi (teknologi yang mendukung CRM), orang (keahlian, kemampuan dan sikap dari orang yang mengatur CRM), proses (proses yang digunakan perusahaan dalam mengakses dan berinteraksi dengan pelanggan dalam menciptakan nilai baru dan kepuasan), pengetahuan dan pemahaman (pendekatan yang digunakan perusahaan untuk menambah nilai pada data konsumen sehingga mereka memperoleh pengetahuan dan pemahaman yang diperlukan untuk memperdalam suatu hubungan).

Pemanfaatan Machine Learning untuk CRM telah banyak digunakan dalam industri manufaktur dan jasa, salah satunya yang dilakukan oleh Abdul Haris Lubis (2016) menggunakan algoritma Kernel K-Means untuk segmentasi pelanggan Kantor Pos Medan. Hidra Amnur (2017) menggunakan algoritma SVM untuk mengoptimalkan profit pada Bank X. Ni Wayan Wardani (2020) dalam bukunya menggunakan beberapa algoritma seperti model RFM dan Naïve Bayes untuk segmentasi pelanggan dalam analytic CRM.

Clustering adalah cara pengelompokkan data ke dalam beberapa cluster berdasarkan unsur kesamaannya. Algoritma clustering merupakan unsupervised learning karena tidak membutuhkan target keluaran dari setiap data. Clustering banyak digunakan di berbagai bidang, seperti bidang kesehatan, statistik, ekonomi dan sebagainya. Clustering menganalisa data terhadap kecenderungan pola-pola data yang sama dan mengelompokkannya. Pola-pola tersebut dikelompokkan ke dalam satu cluster yang memiliki kesamaan sifat dan ciri-ciri yang sama.

Prinsip kerja dari algoritma ini adalah mencari kesamaan pola dari kumpulan data yang diberikan. Algoritma unsupervised machine learning yang digunakan untuk menganalisa data yang diberikan dan menemukan pola kesamaan adalah algoritma K-means clustering.

\section{METODOLOGI}

Metodologi yang digunakan dalam penelitian ini adalah sebagai berikut: 


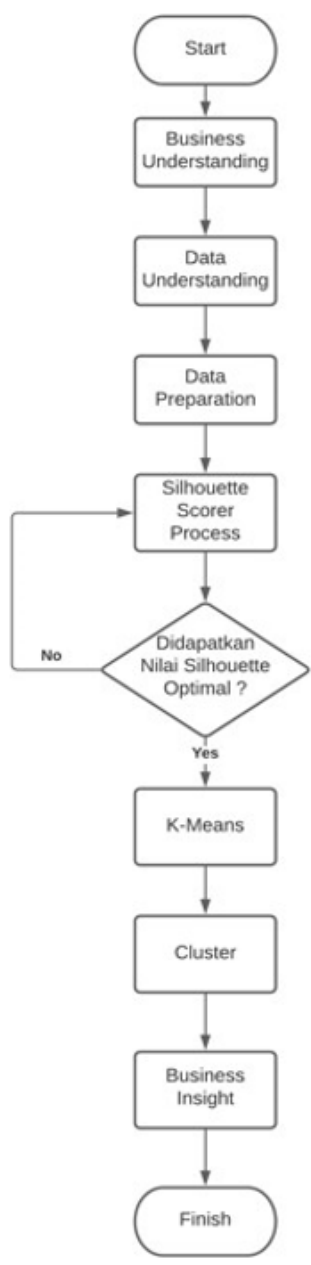

Gambar 1. Diagram Alir Penelitian

\section{A. Business Understanding}

Pada tahapan ini terdiri dari dua bagian, yaitu pemahaman dari tujuan bisnis itu sendiri dan penerjemahan tujuan bisnis tersebut ke dalam data mining.

\section{B. Data Understanding}

Data lapangan yang kemudian dilanjutkan dengan pemahaman mendetil tentang data, mengidentifikasi statistika data kemudian mendeteksi bagian yang menarik untuk dijadikan hipotesa awal.

\section{Data Preparation}

Selanjutnya proses ini terdiri dari kegiatan untuk membangun kumpulan data akhir. Pada tahapan ini dilakukan pembersihan dan transformasi data persiapan sebelum dimasukkan dalam tahap permodelan.

\section{Modelling Clustering}

Selanjutnya, penerapan model clustering dan parameter yang disesuaikan agar didapatkan nilai yang optimal.

\section{E. Eksplorasi data clustering untuk pengembangan Customer Relationship Management.}

Pada proses ini bertujuan untuk mendapatkan insight dari kelompok clustering yang terbentuk, sehingga dari insight tersebut dapat dikembangkan untuk perbaikan CRM. 


\section{HASIL DAN DISKUSI}

Pada bab ini akan dibahas lebih dalam lagi mengenai business understanding, data preparation, modelling, evaluasi dan eksplorasi data clustering untuk pengembangan Customer Relationship Management. Lima tahapan tersebut sebagai berikut:

\section{A. Business Understanding}

Pada tahapan ini, dilakukan pemahaman terhadap tujuan bisnis untuk menentukan pola proses data clustering. Berikut adalah proses tujuan CRM pada PLN XYZ adalah sebagai berikut:

- Meningkatkan konsumsi listrik bagi profitable customer

- Pelanggan yang memberikan keuntungan yang besar, bisa dipertahankan

- Peningkatan strategi pelayanan yang disesuaikan dengan clusteringnya masing-masing.

Selanjutnya, untuk pemahaman segmentasi pelanggan clustering, dibutuhkan pemahaman lebih dalam lagi terhadap tujuan bisnis agar bisa diterjemahkan ke dalam tujuan data mining. Customer segmentation adalah salah satu tujuan data mining yang berkaitan dengan proses CRM.

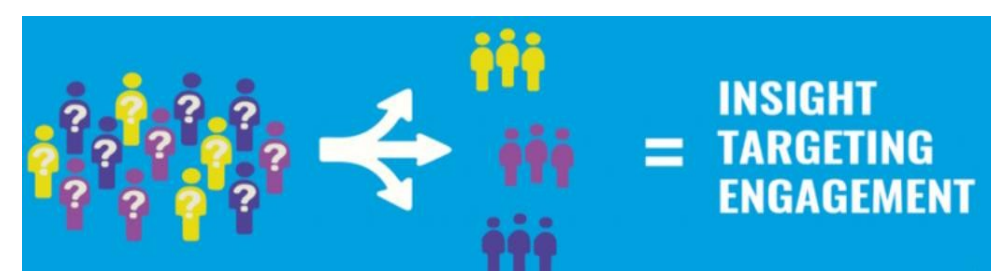

Gambar 2. Segmentasi Populasi

\section{B. Data Understanding}

Pada proses ini, dilakukan identifikasi masalah dalam data. Hasil dari identifikasi data tersebut, bermanfaat untuk mengkonfirmasi distribusi data tersebut apakah seperti yang diharapkan, dan memberikan insight mengenai hal-hal yang perlu dibenahi pada tahap selanjutnya, yaitu Data Preperation. Pada penelitian ini, Data Understanding akan dipetakan dalam sebaran data yang memberikan informasi awal mengenai konsumsi pemakaian listriknya, Data Knowledge awal tersebut akan bisa terlihat hipotesa awalnya.

Pemahaman pada tujuan bisnis dianalisa dengan kondisi data yang ada, untuk kemudian diolah agar mendapatkan hipotesa data yang menarik. Hipotesa awal yang didapat dari data understanding ini ialah pola konsumsi yang beragam apabila dilihat dari persebaran datanya. Maka langkah selanjutnya untuk membuktikan seberapa banyak ragamnya akan diproses pada clustering.

\section{Data Preparation}

Pada tahap persiapan data, platform KNIME akan melakukan query data untuk mendapatkan data yang siap untuk diolah. Data Preparation dilakukan dengan memilih variabel yang ingin dianalisa, melakukan pembersihan data, integrasi, reduksi dan tranformasi data sehingga data tersebut siap untuk diolah oleh algoritma clustering machine learning. Data pelanggan PT. PLN XYZ yang diolah sebanyak 20.035 pelanggan. 
Tabel 1

Data Uji Clustering 20.035 Pelanggan

\begin{tabular}{|c|c|c|c|c|c|c|c|c|}
\hline UNIQID & TARIF & DAYA & PEMKWH_202109 & RPPTL_202109 & RPTAG_202109 & RP/KWH & JAM NYALA_202109 & KWH EMIN \\
\hline Customer 1 & R1M & 900 & 151 & 204,152 & 224567 & 1,352 & 168 & 36 \\
\hline Customer 2 & R1 & 450 & 0 & 2,475 & 2723 & 138 & 0 & 18 \\
\hline Customer 3 & R1M & 900 & 168 & 227,136 & 249850 & 1,352 & 187 & 36 \\
\hline Customer 4 & R1 & 450 & 164 & 36,150 & 39765 & 220 & 364 & 18 \\
\hline Customer 5 & R1M & 900 & 225 & 304,200 & 334620 & 1,352 & 250 & 36 \\
\hline Customer 6 & R1M & 900 & 70 & 94,640 & 104104 & 1,352 & 78 & 36 \\
\hline Customer 7 & R1 & 450 & 147 & 31,942 & 35136 & 217 & 327 & 18 \\
\hline Customer 8 & R1 & 900 & 108 & 48,795 & 53675 & 452 & 120 & 36 \\
\hline Customer 9 & R1M & 900 & 0 & 48,672 & 53539 & 1,352 & 0 & 36 \\
\hline Customer 10 & R1 & 450 & 127 & 26,992 & 29691 & 213 & 282 & 18 \\
\hline Customer 11 & R1 & 1300 & 35 & 75,124 & 82636 & 2,146 & 27 & 52 \\
\hline Customer 12 & R1 & 450 & 49 & 8,430 & 9273 & 172 & 109 & 18 \\
\hline Customer 13 & R1 & 1300 & 112 & 161,806 & 177987 & 1,445 & 86 & 52 \\
\hline Customer 14 & R1M & 900 & 306 & 413,712 & 455083 & 1,352 & 340 & 36 \\
\hline Customer 15 & R1M & 900 & 353 & 477,256 & 524982 & 1,352 & 392 & 36 \\
\hline Customer 16 & R1M & 900 & 9 & 48,672 & 53539 & 5,408 & 10 & 36 \\
\hline Customer 17 & R1M & 900 & 59 & 79,768 & 87745 & 1,352 & 66 & 36 \\
\hline Customer 18 & R1M & 900 & 17 & 48,672 & 53539 & 2,863 & 19 & 36 \\
\hline Customer 19 & R1 & 900 & 224 & 91,860 & 79946 & 410 & 249 & 36 \\
\hline Customer 20 & R1M & 900 & 267 & 360,984 & 397082 & 1,352 & 297 & 36 \\
\hline Customer 21 & R1 & 2200 & 93 & 134,357 & 147793 & 1,445 & 42 & 88 \\
\hline Customer 22 & R1M & 900 & 256 & 346,112 & 380723 & 1,352 & 284 & 36 \\
\hline Customer 23 & R1M & 900 & 258 & 348,816 & 383698 & 1,352 & 287 & 36 \\
\hline Customer 24 & R1M & 900 & 436 & 589,472 & 648419 & 1,352 & 484 & 36 \\
\hline
\end{tabular}

Variabel data yang digunakan untuk mendapatkan memproses clustering segmentasi pelanggan adalah daya, pemakaian kwh September 2021, Rupiah tagihan listrik (murni) September 2021, Rupiah tagihan listrik September 2021, Rupiah/Kwh, Jam nyala September 2021 dan Kwh Emin. Variabel tersebut, menggambarkan pola konsumsi dari tiap pelanggan, sehingga hal itu bisa dijadikan dasar utama membentuk segmentasi pelanggan.

Data tersebut diolah oleh KNIME, kemudian uji korelasi antar variabel untuk mendapatkan insight seberapa kuat nilai korelasi antar variabel tersebut berpengaruh satu sama lainnya.

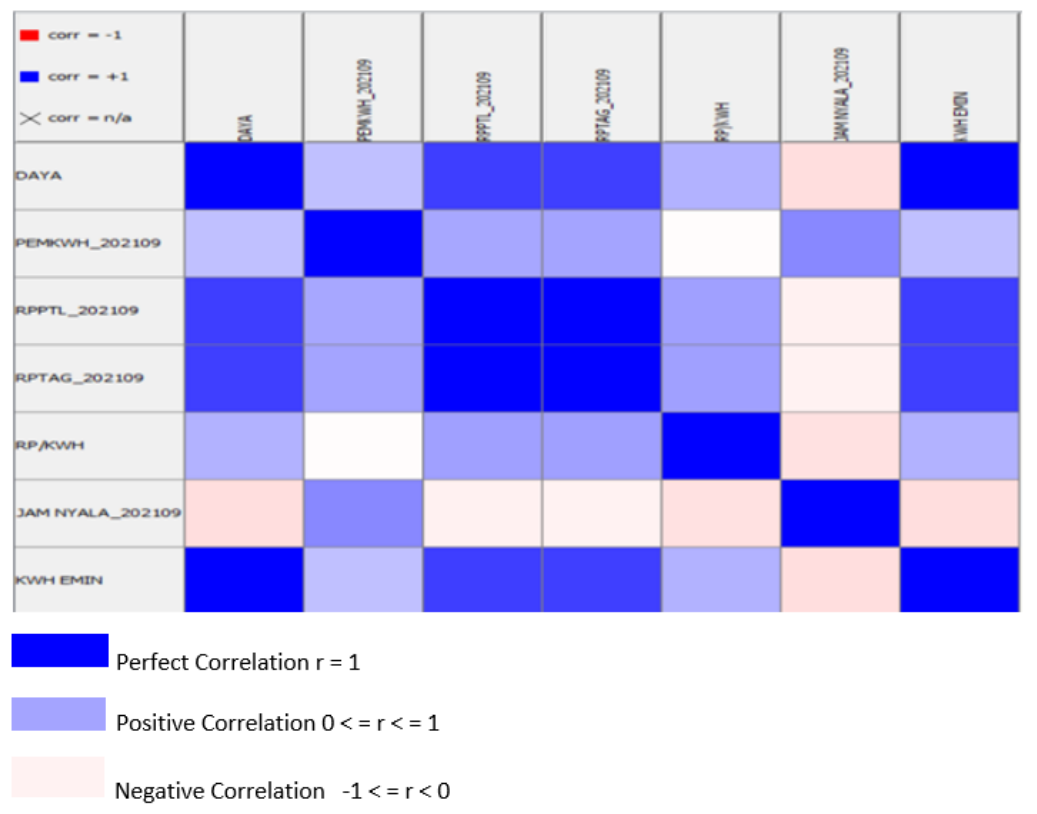

Gambar. 3 Matriks uji korelasi antar variabel data

Pada gambar 3, tingkat pekatnya warna menggambarkan apakah korelasi tersebut menunjukkan perfect correlation, positive correlation ataukah negative correlation. Analisis Korelasi (r) digunakan untuk mengukur tinggi rendahnya derajat hubungan antar variabel yang diteliti. Tinggi rendahnya derajat keeratan tersebut dapat dilihat dari koefisien korelasinya Koefisien korelasi yang mendekati angka +1 berarti terjadi hubungan positif yang erat, bila mendekati angka - 1 berarti terjadi hubungan negatif yang erat. Sedangkan koefisien korelasi mendekati angka 0 (nol) berarti hubungan kedua variabel adalah lemah atau tidak erat. Dengan demikian nilai koefisien korelasi adalah $-1<=\mathrm{r}<=+1$. Untuk koefisien korelasi sama dengan - 1 atau 
+1 berarti hubungan kedua variabel adalah sangat erat atau sangat sempurna.

Pada pengujian korelasi antar variabel, menghasilkan nilai uji korelasi sebagai berikut:

Tabel 2

Nilai Uji Korelasi Antar Variabel

\begin{tabular}{|c|c|c|c|c|c|c|c|}
\hline $\begin{array}{l}\text { NILAI UII } \\
\text { KORELASI }\end{array}$ & $\frac{\pi}{d}$ & 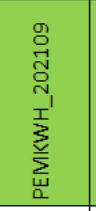 & 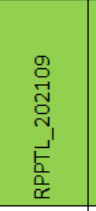 & 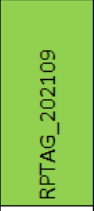 & 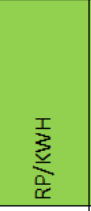 & 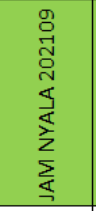 & $\begin{array}{l}\sum_{W}^{Z} \\
\underline{T} \\
\underline{3} \\
\end{array}$ \\
\hline DAYA & 1 & 0.2477 & 0.7552 & 0.7511 & 0.3039 & -0.1276 & 1 \\
\hline PEMKWH_202109 & 0.2477 & 1 & 0.3457 & 0.3556 & -0.0124 & 0.4661 & 0.2477 \\
\hline RPPTL_202109 & 0.7552 & 0.3457 & 1 & 0.9989 & 0.3733 & -0.0543 & 0.7552 \\
\hline RPTAG_202109 & 0.7511 & 0.3556 & 0.9989 & 1 & 0.3745 & -0.0523 & 0.7511 \\
\hline $\mathrm{RP} / \mathrm{KWH}$ & 0.3039 & -0.0124 & 0.3733 & 0.3745 & 1 & -0.1158 & 0.3039 \\
\hline JAM NYALA 202109 & -0.128 & 0.4461 & -0.0543 & -0.0523 & -0.1158 & 1 & -0.128 \\
\hline KWH EMIN & 1 & 0.2477 & 0.7552 & 0.7511 & 0.3039 & -0.1276 & 1 \\
\hline
\end{tabular}

Dari nilai uji korelasi di atas, dapat kita ambil kesimpulan nilai antar variabel mana yang mempunyai hubungan korelasi terkuat. Koefisien korelasi bernilai 0 (nol), berarti tidak ada hubungan antara kedua variabel tersebut. Koefisien korelasi bernilai negatif, berarti hubungan antara kedua variabel tersebut negatif atau saling berbanding terbalik sedangkan Koefisien korelasi bernilai positif, berarti hubungan antara kedua variabel tersebut positif atau saling berbanding lurus.

Selain data korelasi, data variabel bisa dipetakan secara statistik untuk mendapatkan insight yang lebih dalam dari data tersebut. Data pemetaan statistik meliputi, Min, Max, Mean, Median, Standar Deviasi, Skewness, dan Kurtoisis.

Tabel 3

Data Statistik Tiap Variabel

\begin{tabular}{|c|c|c|c|c|c|c|c|c|c|c|c|}
\hline Column & Min & Mean & Median & $\operatorname{Max}$ & Std. Dev. & Skewness & Kurtosis & No. Missing & No. $+\infty$ & No. $-\infty$ & Histogram \\
\hline DAYA & 450 & $1,781.39$ & 900 & 555,000 & $8,422.68$ & 25.9981 & $1,146.62$ & 0 & 0 & 0 & \\
\hline PEMKWH_202109 & 0 & 150.3641 & 113 & 998 & 145.7543 & 2.5486 & 8.5355 & 0 & 0 & 0 & \\
\hline RPPTL_202109 & 2,475 & $268,029.37$ & 113,568 & $51,892,140$ & $1,178,875.00$ & 20.2504 & 547.375 & 0 & 0 & 0 & \\
\hline RPTAG_202109 & 0 & $290,918.17$ & 124,650 & $51,892,140$ & $1,232,556.48$ & 19.4983 & 504.571 & 0 & 0 & 0 & \\
\hline RP/KWH & 137.5 & $1,911.60$ & 1,352 & $723,794.50$ & $11,830.71$ & 33.9135 & $1,475.46$ & 0 & 0 & 0 & \\
\hline JAM NYALA_20210 & 0 & 145.2185 & 132.222 & $1,215.56$ & 100.77 & 0.9802 & 2.1573 & 0 & 0 & 0 & \\
\hline & & & & & & & & & & & $1.216^{\circ}$ \\
\hline
\end{tabular}

Dari data statistik tersebut, dapat dibuat histogram untuk melihat sebaran data agar lebih mudah untuk memahami karakter kuantitatif dari data tersebut. Tabel di atas selain menunjukkan sifat statistik dari 
tiap variabel data, juga dapat digunakan untuk mengecek dataset yang diolah dalam clustering tidak ada missing value dan data tak terhingga. Hal ini termasuk tahapan preprocessing data dalam machine learning.

\section{Model Clustering}

Melakukan proses Silhoutte Scorer dengan 2 model workflow, yaitu model Silhouette Coeficient (closed loop) dan model Optimized K-means Coeficient (open loop). Hasil dari 2 model adalah sebagai berikut:

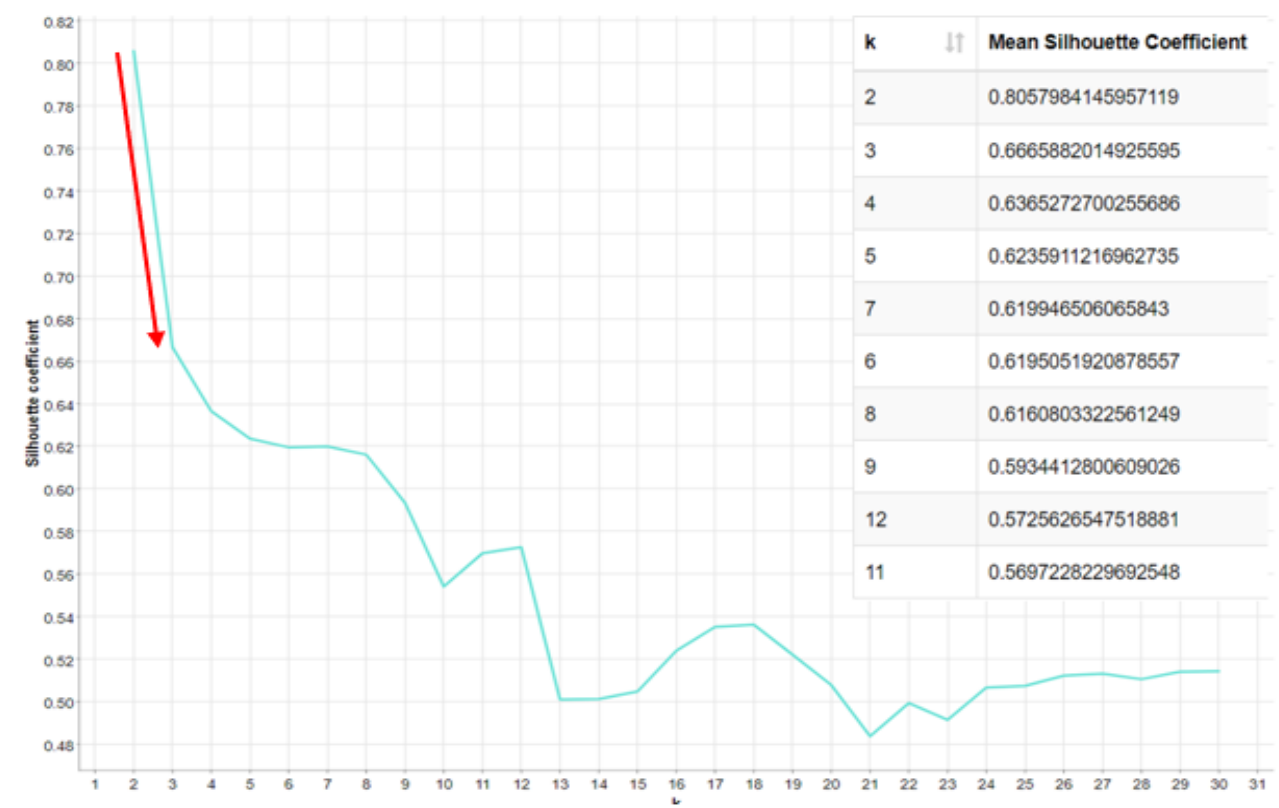

Gambar 5. Hasil nilai model Silhouette Coeficient (closed loop) scorer

Pada model Silhouette Coeficient (closed loop) scorer ini, mendapatkan nilai optimal Silhouette Coeficient 0.8058 dengan nilai $\mathrm{k}=2$ (terbentuk 2 clustering). Dari grafik juga dapat dilihat, penurunan yang paling besar adalah pada $\mathrm{k}=2$.

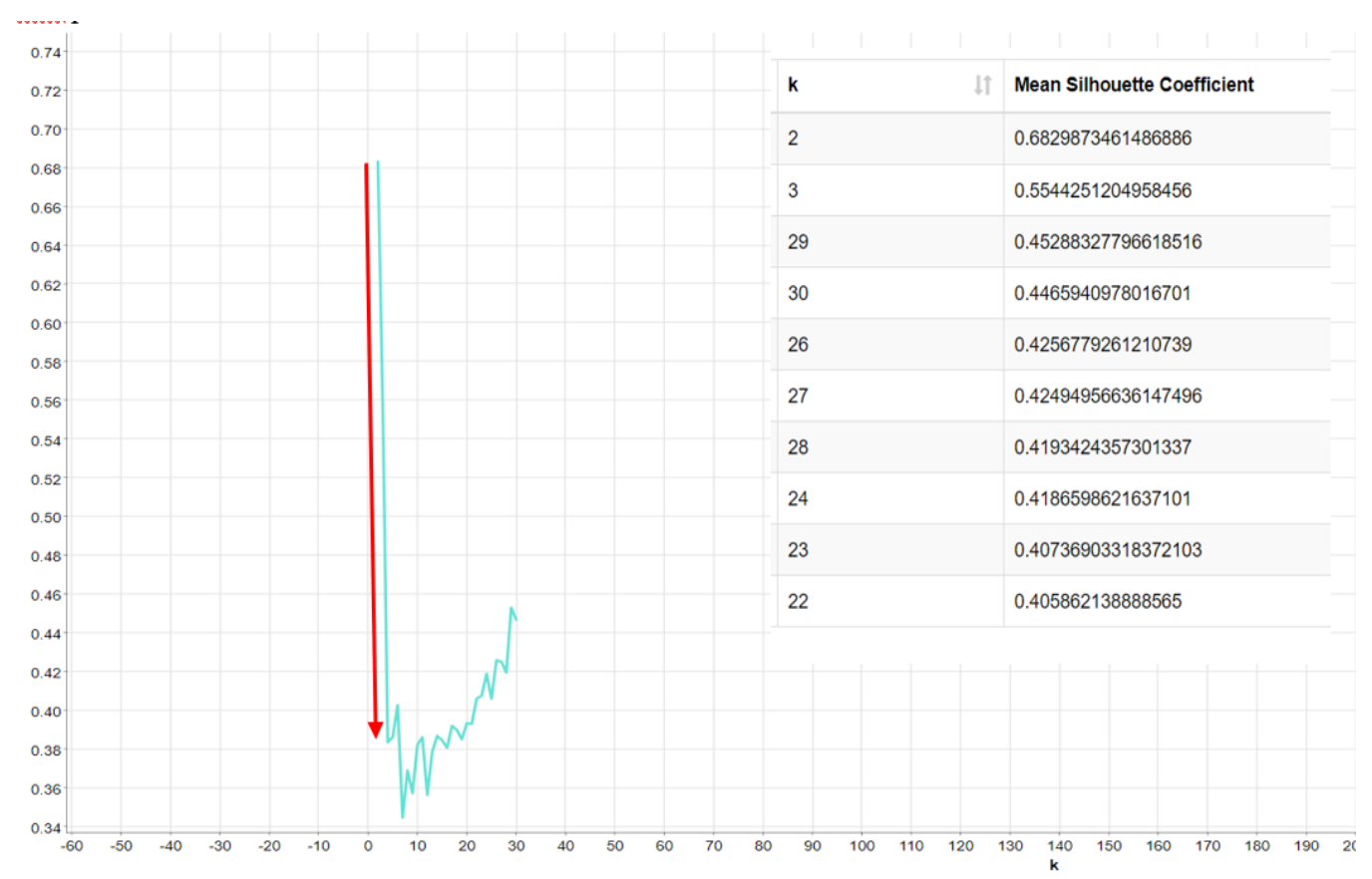

Gambar 6. Hasil nilai model Optimized K-means Coeficient (open loop) 
Sedangkan untuk pada model Optimized K-means Coeficient (open loop) scorer ini, optimal Silhouette Coeficient 0.6830 dengan nilai $\mathrm{k}=2$ (terbentuk 2 clustering). Dari grafik juga dapat dilihat, penurunan yang paling besar adalah pada $\mathrm{k}=2$.

Berdasarkan hasil nilai silhouette pada gambar 7, menunjukkan plot 3 dimensi dengan clusterisasi berdasarkan daya, rupiah tagihan dan pemakaian kwh. Terbentuk 2 kelompok clustering berdasarkan algoritman K-means.

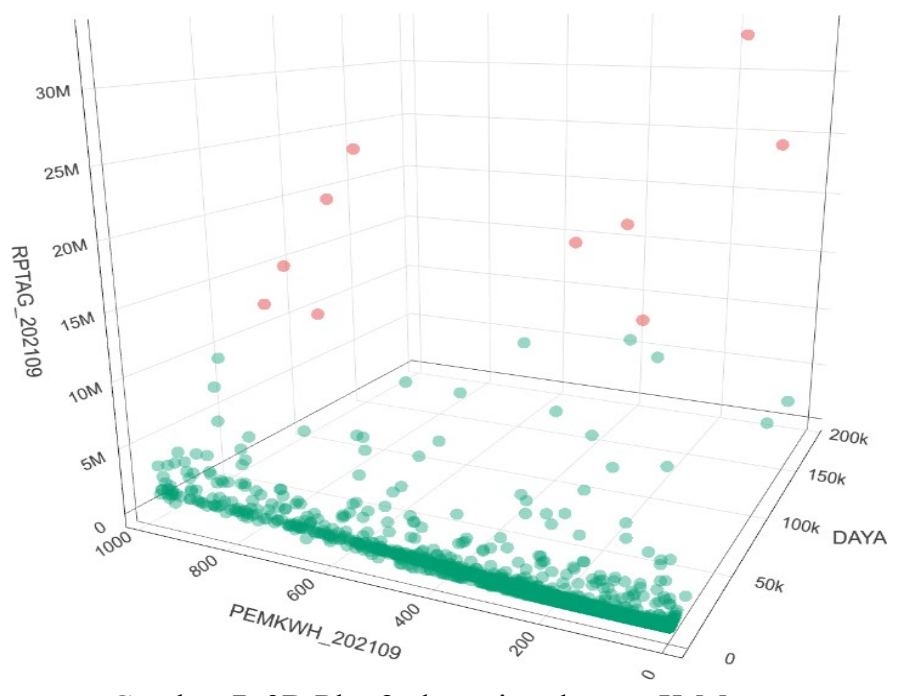

Gambar 7. 3D Plot 2 clustering dengan K-Means

\section{E. Eksplorasi data clustering untuk pengembangan Customer Relationship Management}

Berdasarkan hasilnya, didapatkan beberapa kesimpulan yaitu PLN XYZ dengan populasi pelanggan 20.035 pelanggan, dilakukan segmentasi customer berdasarkan data konsumsi listrik. Hasil segmentasi menggunakan K means didapatkan 46 pelanggan, yang merupakan profitable customer dan clustering kedua sebanyak 19.989 pelanggan ialah less-profitable customer. Profitable customer adalah pelanggan yang mempunyai pola konsumsi pemakaian tenaga listrik yang besar tiap bulannya, dengan kriteria DAYA terpasang tinggi (diatas 23.000 VA) dan RPTAG_202109 tinggi (di atas Rp 10.598.174), begitupun pula sebaliknya untuk less-profitable customer. Cluster pertama, profitable customer, merupakan perusahaan pada sektor industri Penggilingan Padi, Perkantoran Pemerintah Daerah, Rumah sakit dan Pabrik Tepung Beras. Sedangkan, untuk kelas less-profitable customer, dominasi pelanggan rumah tangga. Tahapan selanjutnya adalah targeting untuk menentukan target pasar berdasarkan profitable customer atau less-profitable customer. Tabel 5 menunjukkan 2 program yang dapat diterapkan untuk profitable customer berdasarkan tipe customer.

Tabel 5

Strategi Hubungan Pelanggan

\begin{tabular}{|c|c|c|}
\hline $\begin{array}{c}\text { Tipe } \\
\text { Customer }\end{array}$ & $\begin{array}{c}\text { Continuity } \\
\text { Marketing }\end{array}$ & $\begin{array}{c}\text { One To One } \\
\text { Marketing }\end{array}$ \\
\hline Profitable & Bisnis ToBisnis & $\begin{array}{c}\text { Customer } \\
\text { Business } \\
\text { Development }\end{array}$ \\
\hline Less Profitable & Continuous & Retail Account \\
Customer & Replenishment & Marketing \\
& Program & \\
\hline
\end{tabular}

Terdapat dua program sebagai strategi hubungan pelanggan sebagai berikut:

1. Pemasaran Berkelanjutan (Continuity Marketing)

Konsep Continuous Replenishment Program (CRP) digunakan untuk pelanggan Less-Profitable Customer. Sedangkan untuk pelanggan profitable customer menggunakan strategi Sourcing. Ketika perusahaan tepat dalam memilih strategi maka akan berefek peningkatan profit dan mempertahankan 
pelanggan. Sebagai berikut:

- Continuous Replenishment Program - Less Profitable

Dalam hal ini perlu diterapkan program program partnership untuk mendorong peningkatan konsumsi pemakaian energi pada pelanggan, seperti partnership dengan toko elektronik berupa voucher pembelian peralatan listrik, partnership dengan produsen alat elektronik untuk program subtitusi peralatan non listrik menjadi berbasis energi listrik (kompor listrik, mesin jahit listrik, Electric Vehicle, dil).

- Business to Business - Profitable

Tipe pelangggan ini akan ditingkatkan pemakaian energinya dengan menawarkan produk layanan premium tanpa padam, serta memberikan account eksekutif khusus kepada pelanggan untuk meningkatkan pelayanan, sehingga kepercayaan pelanggan meningkat dan semakin loyal. Kemudian PLN bisa melakukan upaya penurunan biaya pokok penyediaaan dan penyaluran listrik ke pelanggan.

2. Pemasaran Individual (One To One Marketing)

Yakni pemasaran individu yang dilakukan dengan memanfaatkan teknologi informasi untuk berinteraksi kepada pelanggan. Dengan sistem informasi database mengenai profil pelanggan, perusahaan dapat membuat strategi pelayanan pelanggan untuk memenuhi kebutuhan pelanggan.

- Customer Business Development digunakan untuk pelanggan Profitable. Customer business development melakukan penilaian terkait manfaat dari proses bisnis marketing, finance, management, dan customer service oleh Key Account Marketing (KAM). Tujuannya yakni untuk masuk lebih jauh dalam business development pelanggan dengan memberikan solusi terbaik dan konsultasi mengenai sistem kelistrikan untuk mendukung pengembangan bisnis customer PLN.

- Konsep Retail Account Management (RAM) digunakan untuk pelanggan Less-Profitable. Artinya melihat pelanggan tersebut sebagai mitra untuk mengembangkan peluang bisnis. Dalam hal ini PLN harus melakukan profiling pelanggan lebih jauh dengan menggunakan CRM yang telah terintegrasi pada PLN Mobile masing masing ID Pelanggan. Informasi produk layanan yang sesuai dengan profil pelanggan akan semakin mudah didapatkan.

\section{KESIMPULAN}

Dari hasil pembahasan, didapatkan kesimpulan bahwa PT PLN XYZ mempunyai 20.035 pelanggan. Hasil dari K-means terbentuk 2 clustering. Clustering pertama sebanyak 46 pelanggan yang merupakan pelanggan profitable dan clustering kedua sebanyak 19.989 pelanggan ialah less-profitable customer. Profitable customer adalah pelanggan yang mempunyai pola konsumsi pemakaian tenaga listrik yang besar tiap bulannya, dengan kriteria DAYA terpasang tinggi (di atas 23.000 VA) dan RPTAG_202109 tinggi (di atas $\mathrm{Rp}$ 10.598.174), begitupun pula sebaliknya untuk less-profitable customer. Dari hasil tersebut, maka dapat ditentukan masing-masing target pasarnya. Cluster pertama, profitable customer, merupakan perusahaan pada sektor industri Penggilingan Padi, Perkantoran Pemerintah Daerah, Rumah sakit dan Pabrik Tepung Beras. Sedangkan, untuk kelas less-profitable customer, dominasi pelanggan rumah tangga. Strategi pelayanan profitable customer terntunya berbeda dengan strategi pelayanan untuk less profitable customer. Untuk profitable customer menggunakan pendekatan Business to Business dan Customer Business Development, Sedangkan untuk less profitable customer, menggunakan Continuous Replenishment Program dan Retail Account Marketing

\section{DAFTAR PUSTAKA}

Abdul Haris Lubis. (2016), Model Segmentasi Pelanggan Dengan Kernel K-Means Clustering Berbasis Customer Relationship Management, Jurnal \& Penelitian Teknik Informatika Volume 1 Nomor 1

Aggelis, Vasilis dan Christodoulakis. (2005). "Customer Clustering using RFM Analysis", Proceedings of the 9th WSEASInternational Conference on Computers. (ICCOMP'05).

Aulia Dewi Savitri, Fitra Abdurrachman Bachtiar, Nanang Yudi Setiawan. (2018), Segmentasi Pelanggan Menggunakan Metode K-Means Clustering Berdasarkan Model RFM Pada Klinik Kecantikan.

Birant, Derya. (2011). Data Mining Using RFM Analysis, Knowledge-Oriented Applications in Data Mining. 
Dokuz EylulUniversity Turkey.

Daniel Pradipta Hidayatullah, Retno Indah Rokhmawati, Andi Reza Perdanakusuma. (2018), Analisis Pemetaan PelangganPotensial Menggunakan Algoritma K-Means dan LRFM Model Untuk Mendukung Strategi Pengelolaan Pelanggan.

Debora Agustina, Darminto Pujotomo, Diana Puspitasari. (2017), Pengembangan Strategi Hubungan Pelanggan Berdasarkan Segmentasi Pelanggan Menggunakan Data Mining.

Gordon, Ian. (2002). Best Practices: Customer Relationship Management. Ivey Business Journal.

Han, Jiawei dan Kamber, Micheline. (2006). Data Mining : Concept and. Techniques Second Edition, Morgan Kaufmann Publishers.

Hidra Amnur. (2017), Customer Relationship Management and Machine Learning technology for Identifying the Customer, International Journal On Informatics Visualization Vol 1 No 1

Kartika Imasari, Kezia Kurniawati Nursalin, (2011). Pengaruh Customer Relationship Management Terhadap Loyalitas Pelanggan Pada PT BCA Tbk. Fokus Ekonomi (FE) Desember 2011 Vol. 10, No. 3, $183-192$

Kotler, P.\& Kevin L.K., (2008). Manajemen Pemasaran (edisi 13 jilid 1). Jakarta. Erlangga.

Li, D. C., Dai, W. L., \& Tseng, W. T. (2011). A two-stage clustering method to analyze customer characteristics to build discriminative customer management: A case of textile manufacturing business. Expert Sistems with Applications, 38(6), 7186-7191.

Marcus, C. (1998). A practical yet meaningful approach to customer segmentation. Journal of Consumer Marketing, 15(5), 494-504.

Ni Made Anindya Santika Devi, I Ketut Gede Darma Putra, I Made Sukarsa. (2015), Implementasi Metode Clustering DBSCAN pada Proses Pengambilan Keputusan.

Ni wayan Wardani. (2020), Penerapan Data Mining dalam Analytic CRM, Yayasan Kita Menulis.

P. N. Tan, M. Steinbach dan V. Kumar. (2005). Introduction to Data Mining, Boston: Addison-Wesley LongmanPublishing Co.

Peppard, J. (2000). Customer relationship management (CRM) in financial services. European management Journal, 18(2),312-327. 